\title{
CASO PARA ENSINO COMO METODOLOGIA ATIVA EM ADMINISTRAÇÃOO
}

\author{
TEACHING CASE AS AN ACTIVE METHODOLOGY FOR BUSINESS
}

Recebido em 28.06.2017. Aprovado em 12.07.2017
Avaliado pelo sistema double blind review
DOI: http://dx.doi.org/10.12712/rpca.v11i3.1006

\section{Antonio Messias Valdevino}

messiasurca@gmail.com

Universidade Federal da Paraíba (UFPB), João Pessoa/PB, BRASIL

\section{Halana Adelino Brandão}

halana.brandao@ufca.edu.br

Universidade Federal do Cariri (UFCA), Juazeiro do Norte/CE, BRASIL

\section{Jailson Santana Carneiro}

jailson192@gmail.com

Universidade Federal da Paraíba (UFPB), João Pessoa/PB, BRASIL

\section{Ítalo Anderson Taumaturgo dos Santos}

italotaumaturgo@gmail.com

Universidade Federal do Cariri (UFCA), Juazeiro do Norte/CE, BRASIL

\section{Webert Jannsen Pires de Santana}

webertjannsen@gmail.com

Fundação Getúlio Vargas (FGV - EAESP), São Paulo/SP, BRASIL

\section{Resumo}

Este trabalho busca avaliar a estratégia do caso para ensino como uma metodologia ativa no desenvolvimento de habilidades em alunos de um curso de administração de uma Universidade Pública, localizada no estado do Ceará. Para que fosse dada tal avaliação, ocorreu o uso da referida estratégia em três disciplinas, sendo elas duas obrigatórias e uma optativa. Posteriormente, aplicou-se um questionário entre os 80 participantes que foram submetidos a esta metodologia, levantando hipóteses acerca do desenvolvimento de habilidades nos alunos através da utilização de casos para ensino. $\mathrm{O}$ procedimento metodológico, que se tratou de um teste de hipóteses, apontou resultados que confirmaram a influência positiva no desenvolvimento de habilidades nos alunos quando há predisposição destes para o uso do caso, enfatizando que por meio da discussão de um caso é possível melhorar a argumentação, e que o uso do caso é oportuno para melhorar a capacidade de comunicação, bem como a capacidade gerencial dos alunos.

Palavras-chave: Caso para ensino. Administração. Ensino de marketing.

\section{Abstract}

This paper aims to evaluate the strategy of the Teaching Case as an active methodology in the development of skills in students of an undergraduate business school of a Public University, located in the state of Ceará. In order to be achieved such evaluation, the strategy was used in three disciplines, of which two were required in the curriculum and one was elective. Subsequently, a questionnaire was applied among the 80 participants who were submitted to this methodology, raising hypotheses about the development of skills in the students through the use of the Teaching Case. The methodological procedure, which was a test of hypotheses, pointed out results that confirmed the positive influence on the development of skills in the students when they are predisposed to the use of the case, emphasizing that through the discussion of a case it is possible to improve the argumentation, and that the use of the case is opportune to improve the communication capacity as well as the managerial capacity of the students.

Keywords: Teaching case. Business. Marketing teaching. 


\section{Introdução}

Encontra-se nos casos para ensino uma forma de contextualização com a teoria e a prática, usando recursos próximos do ambiente em que o discente está inserido. O caso, de acordo com Roesch e Fernandes (2007), trata-se da reconstrução de uma situação que pode envolver um problema de gestão ou conflitos para fins didáticos. Deste modo, o caso é escrito, usado e aceito como ferramenta pedagógica, e de acordo com a literatura, no Brasil, principalmente em cursos de pós-graduação (IKEDA; VELUDODE-OLIVEIRA; CAMPOMAR, 2007.)

A estratégia foi retomada e existe incentivo tanto para o uso, quanto para a elaboração destes, ganhando fôlego desde 2007 devido ao aumento de cursos de pós-graduação e eventos que criaram linhas específicas para o tema, como os da Associação Nacional de PósGraduação e Pesquisa em Administração (ANPAD), a qual registrou durante o período de 2007 a 2011 um total de 107 casos para ensino publicados (ROESCH; FERNANDES, 2007; FARIA; FIGUEIREDO, 2013). Tendo em vista as possibilidades de uso e aplicabilidade da metodologia, este trabalho busca responder a seguinte questão: os alunos reconhecem a estratégia de caso para ensino como uma metodologia efetiva no desenvolvimento de habilidades?

Neste sentido, este trabalho tem como objetivo avaliar a estratégia do caso para ensino como uma metodologia ativa de ensino no desenvolvimento de habilidades em alunos de um curso de administração de uma Universidade Pública, localizada no estado do Ceará. Para tal análise, o caso foi aplicado em três disciplinas deste curso, uma optativa e duas obrigatórias. De acordo com o Plano Pedagógico do Curso (PPC), e atendendo uma resolução do Conselho Nacional de Educação, os cursos de Administração devem contemplar conteúdos que relevem interrelações com a realidade nacional e devem ser analisados sob uma perspectiva histórica e contextualizados da sua aplicabilidade. Para tanto, nas suas disciplinas obrigatórias devem estar inclusos os conteúdos de formação básica, de formação profissional e de estudos quantitativos e suas tecnologias. Enquanto as disciplinas optativas são usadas para a formação complementar, além de possuir caráter transversal e interdisciplinar, que visam o enriquecimento do perfil do formando em Administração (PPC, 2006).

As disciplinas obrigatórias são Administração Mercadológica I e II, do sexto e sétimo semestres, cujos objetivos consistem em oferecer ao aluno as condições cognitivas e reflexivas que o capacitem à compreensão e ao atendimento das necessidades do mercado, além de fornecer instrumental para o desenvolvimento das atividades da função mercadológica das organizações. A disciplina optativa é Gestão de Serviços, que tem como objetivo orientar o estudante para a formação de um quadro conceitual e prático sólido, permitindo discussão das especificidades das organizações de serviços. Além disso, busca-se discutir também acerca da administração de serviços, processo de criação, desenvolvimento e lançamento de novos serviços (PPC, 2006).

Com efeito, o uso do caso para ensino no curso de administração da universidade pesquisada está em processo de consolidação. Portanto, a avaliação da aplicação desta estratégia no curso permite um diagnóstico de suas forças e fraquezas ao usá-lo em tais disciplinas, podendo então, incentivar a replicação da metodologia em outras disciplinas e em outros cursos de graduação da Universidade.

\section{Revisão bibliográfica}

\section{Ensino em Administração}

No Brasil, os cursos de Administração têm uma história recente, tendo um pouco mais que meio século de atuação no país. No decorrer desta sessão se busca apresentar um pouco da história da profissão do administrador, bem como da estruturação dos cursos de Administração no Brasil no decorrer dos 63 anos, desde quando foram instalados.

Em 2015 se comemorou o jubileu de ouro da Administração. Em 09 de setembro de 1965 foi regulamentada a profissão do Administrador, pela lei de $n^{\circ}$ 4.769, lei que também cria o Conselho Federal de Administração (CFA), sendo este uma autarquia de personalidade jurídica, responsável por, além de outros, orientar e disciplinar o exercício da profissão. Embora a profissão somente tenha sido regulamentada em 1965, o ensino em administração começou 13 anos antes, no ano de 1952. O currículo mínimo para o curso foi aprovado em 1966, passando por alteração em 1993 e teve suas propostas de diretrizes curriculares para os cursos de graduação em Administração apresentadas em 1998 (HISTÓRIA..., 2014).

Curado (2001) aponta que a teoria organizacional foi moldada como sendo um saber científico, e que 
o processo de construção desse saber ocorre pelas buscas das regularidades vividas, ou manifestadas, dentro das organizações. Ele ainda aponta que o saber administrativo se diferencia dos demais saberes, tendo em vista que as organizações estão voltadas para fins específicos e suas ações estão norteadas para estes fins. Ao buscar desenvolver o saber administrativo, ainda em conformidade com o autor, a administração empresta de outras áreas do conhecimento o seu ferramental teórico e metodológico. Dentre estas áreas está o Marketing, a Psicologia, a Antropologia, a Matemática, a Sociologia, a Biologia, a Economia, entre outros.

Em consonância ao que foi abordado anteriormente, e seguindo as Diretrizes Curriculares Nacionais do Curso de Graduação em Administração, os conteúdos adotados pela instituição para a formação do administrador são de Formação Básica, relacionando-se com estudos antropológicos, filosóficos, psicológicos, ético-profissionais, políticos, comportamentais, econômicos e contábeis, bem como os relacionados com as tecnologias da comunicação e da informação e das ciências jurídicas; Formação Profissional, que se relaciona com áreas especificas e envolve teorias da administração e das organizações, administração de recursos humanos, mercado e marketing, materiais, produção e logística, financeira e orçamentária, sistemas de informações, planejamento estratégico e serviços; Conteúdos de Estudos Quantitativos e suas Tecnologias, que abordam pesquisas operacionais, teoria dos jogos, modelos matemáticos e estatísticos, entre outros. Além de conteúdos de Formação Complementar, que tratam de estudos opcionais de caráter transversal e interdisciplinar, visando o enriquecimento do perfil do profissional de administração (PPC, 2006).

Com isso, de acordo com o Projeto Pedagógico do Curso de Administração da Universidade estudada neste trabalho, busca-se formar um bacharel em Administração capaz de compreender as questões científicas, técnicas, sociais e econômicas da produção e de seu gerenciamento sistemático. Este ainda deve ser capaz de observar as necessidades setoriais e gerais, que demandam processos de tomada de decisões, desenvolvendo o processo de gerenciamento e assimilação de novas informações, apresentando flexibilidade intelectual e adaptabilidade contextualizada.

Dito isto, faz-se necessário decidir as ferramentas pedagógicas que devem ser utilizadas no processo de ensino-aprendizagem. Tal definição parte, em geral, do professor, levando em consideração o objetivo da disciplina, a necessidade do curso e os recursos que estão disponíveis para o docente neste processo (GALLON; RODRIGUES, 2008). As metodologias de ensino que são comumente utilizadas em cursos de graduação em Administração são apresentadas na seção seguinte.

\section{Metodologias de Ensino em Administração}

A escolha das práticas pedagógicas a utilizar no processo de ensino-aprendizagem depende muito do espaço onde o sujeito está inserido, levando-se em consideração, também, os recursos e as necessidades de cada curso e/ou instituição. Gallon e Rodrigues (2008) afirmam que esta é uma discussão atual e leva as instituições a repensar seus métodos, suas técnicas e seus recursos que podem e devem auxiliar neste processo. A decisão pelo método a ser aplicado em sala de aula ocorre quando já se têm definidos os objetivos educacionais, ou seja, quando o docente decide o que pretende mostrar e as habilidades que seus discentes sejam capazes de realizar ao concluir a disciplina.

Existem diversas metodologias usadas em cursos de Administração que podem auxiliar os professores na integração com seus alunos, a fim de se atingir os objetivos de determinada disciplina e desenvolver as competências que devem ser adquiridas pelos discentes. As possibilidades existentes são muitas, e conforme Silva e Domingues (2006), Gallon e Rodrigues (2008) e Plebani e Domingues (2008), os métodos que são frequetemente utilizados em tais cursos são:

- Aula expositiva, que é mais usual pelo seu baixo custo, e trata-se da apresentação oral de determinado assunto, de forma lógica e estruturada dirigida do professor ao aluno;

- Aula prática de campo, que insere o discente no ambiente e provoca a interação e a observação de fenômenos que ocorrem durante o processo de estudo;

- Trabalho em grupo, que tem o favorecimento do debate e da crítica, além de desenvolver habilidades de organização de informações e construção de uma contextualização sobre o tema estudado; 
- Palestras, onde se apresentam, de forma oral, um conteúdo ao discente, com o apoio de recursos audiovisuais, que complementam o assunto que já é abordado em sala de aula;

- Seminários, onde um grupo reduzido de alunos recebe um tema dado pelo professor, e investiga, estuda o conteúdo para posteriormente apresentar os resultados através de apresentações, exposições ou conversação;

- Discussões, que buscam desenvolver, a partir do debate em sala de aula acerca do tema abordado, de forma dinâmica a percepção dos alunos e encorajá-los a participar;

- Estudo dirigido, que é dado sob a orientação do professor, onde é permitido estudar e sanar dúvidas sobre o objeto de estudo;

- Dissertação, busca desenvolver o senso de interpretação dos discentes, e faz com que estes busquem nos autores a compreensão do estudo e narrar de formas objetivas as ideias centrais.

- Jogos de empresas, que estimulam a compreensão do ambiente empresarial e as variáveis que afetam as empresas. É destinada à formação complementar do discente;

- Resolução de exercícios, que apresenta ao aluno um determinado problema e estimula-o a encontrar uma resolução cabível;

- Simulações, que desenvolvem estudos e ações num ambiente controlado e sem riscos. O intuito é testar determinadas situações e as possíveis reações que podem, ou não, ocorrer;

- Método do role play, jogo de papéis ou dramatização, trata-se de uma encenação/ dramatização onde os alunos assumem papéis, e através de improvisação formulam falas e comportamentos, explorando um determinado contexto de estudo;

- Método do caso, que consiste na oferta de casos a grupos de alunos, que farão questionamentos, interpretações e responderão a uma série de questões elaboradas previamente. Em geral, trata-se de uma situação real de negócio vivida por uma empresa, em um dado momento. E, por fim, apresenta informações relativas à situação a ser analisada.
Dos métodos apresentados o mais usual é o da aula expositiva. Uma explicação para o uso deste método é pela série de variações que este tem, além de seu baixo custo, podendo se adequar à maioria dos conteúdos e ser usado junto a outras ferramentas pedagógicas.

Nos programas de graduação e de pós-graduação em administração, as metodologias ativas têm ganhado espaço principalmente em resposta à preocupação em desenvolver nos alunos a habilidade de lidar com a complexidade dos ambientes nos quais as decisões empresariais são tomadas (AMBROSINI; BOWMAN; COLLIER, 2010).

Dentro deste contexto, uma estratégia ativa utilizada por professores de administração é o caso para ensino, que descentraliza o docente como principal figura no ensino e aloca o aluno como agente protagonista de sua aprendizagem (GREENHALGH, 2007). Evidenciase como proposta metodológica o método do caso, que permite a interação e a ação, destacando-se o trabalho em equipe, a análise, a negociação e a tomada de decisão (PLEBANI; DOMINGUES, 2008).

Neste sentido, é valido afirmar que a estratégia do caso para ensino, uma metodologia ativa na relação de ensino e aprendizagem, é diferente do estudo de caso, que se configura como uma investigação empírica que investiga um fenômeno contemporâneo dentro de um contexto de vida real, sendo que os limites de tais contextos e fenômenos não estejam claramente definidos (YIN, 2005). Ademais, Kruel e Santos (2008) vêem o caso para ensino como uma ferramenta do método do caso, conforme será apresentado e discutido na próxima sessão.

\section{Caso para Ensino}

O método do caso é uma metodologia andragógica, termo que remete a um conceito de educação voltada ao adulto, em contraposição à pedagogia, que se refere à educação de crianças, de aprendizagem ativa que põe o leitor/aluno/participante no papel de um tomador de decisão, o qual enfrenta um problema ou uma oportunidade. O método tem como base o caso, ou seja, a descrição de uma situação real enfrentada por um gestor, assim como os fatos do contexto ambiental, os stakeholders que influenciam a decisão, as opiniões, e outras informações relevantes para o processo de tomada de decisão (CURADO, 2001).

Este método insere-se na perspectiva humanista de educação, que é fundamentada na crença de que os alunos não são seres passivos, prontos para ser 
modelados pelos professores. Um dos fundamentos do método de caso é a crença na capacidade que os alunos têm para o desenvolvimento de habilidades por meio de suas experiências pessoais e por intermédio da experiência prática (GIL, 2004).

Aceita-se esse método como uma estratégia educacional capaz de desenvolver estímulos, motivar, promover a participação ativa, bem como oferecer reais oportunidades de feedback e de transferência de aprendizado (KRUEL; SANTOS, 2008; HAWES, 2004). O caso, em geral, apresenta uma situação vivenciada por uma organização, e que a partir daí o discente passa a entender, conhecer as realidades organizacionais e colocar em confronto os ensinamentos adquiridos em sala de aula.

Em administração, o método do caso é designado a fornecer a base de análise para o processo de tomada de decisão sob uma variedade de condições, sendo útil para ajudar os estudantes a desenvolver um entendimento do problema e a implementação da solução selecionada (IKEDA; VELUDO-DEOLIVEIRA; CAMPOMAR, 2005). Diante disso, encontra-se no caso para ensino uma forma de contextualização da teoria com a prática, usando recursos próximos do ambiente em que o estudante está inserido.

O caso para ensino em Administração, de acordo com Roesch e Fernandes (2007), consiste na reconstrução de uma situação que envolva um problema de gestão da organização para fins didáticos. Em um caso para ensino podem ser abordados diversos conflitos, em várias áreas, desde uma decisão de carreira de um determinado executivo a impactos maiores como uma reestruturação organizacional.

Um caso para ensino é a descrição de uma situação real com objetivos educacionais, comumente envolvendo uma decisão, um problema ou uma oportunidade vivida por alguém em uma organização. Por meio dos casos, $\mathrm{o}$ aluno pode vivenciar situações similares às que são encontradas nas empresas, mas sem correr os riscos que estão relacionados às decisões a serem tomadas no mundo real (FARIA; FIGUEIREDO, 2013).

O uso de casos para ensino teve início na Escola de Direito da Universidade de Harvard, em 1924, bem como pontuam a importância de tal método, por trazer características reais e/ou verossímeis que estimulam a participação do discente, deixando em segundo plano o ensino focado no professor (CHANG, 2003;
CHANG; JENNINGS; TO; SUN, (2005); KRUEL; SANTOS, 2008).

Levando-se em consideração o que fora exposto no texto, até então, elencam-se as hipóteses levantadas por este estudo:

H1: A predisposição para o uso do caso para ensino pelos alunos influencia positivamente no desenvolvimento de habilidades dos mesmos.

H2: A preparação dos alunos para o uso do caso para ensino na sala de aula influencia positivamente no desenvolvimento de habilidades dos mesmos.

H3: A formatação do caso para ensino influencia positivamente no desenvolvimento de habilidades nos estudantes.

O êxito da aplicação do método do caso depende da adequação do mesmo aos objetivos educacionais pretendidos. Por essa razão, é fundamental que o docente seja capaz de selecionar o tipo de caso que se adéque melhor à situação de ensino-aprendizagem em questão. Percebe-se que, não raras vezes, o caso para ensino é aplicado sem a devida ligação com a teoria e com os conceitos, o que pode levar a decisões apenas com base no "bom senso", sem preparar o aluno para as diferentes situações que ele enfrentará no processo administrativo (IKEDA; VELUDO-DE-OLIVEIRA; CAMPOMAR, 2005).

O processo de aprendizagem pode sofrer variações motivacionais na busca do saber de acordo com a interação professor e aluno. $\mathrm{O}$ ambiente em que o discente está inserido e o instrumento utilizado também proporcionam influências neste processo (SILVA; DOMINGUES, 2006). Desta forma, a metodologia empregada como forma de ensino influencia diretamente na aprendizagem do discente.

De acordo com Roesch e Fernandes (2007) a difusão do caso para ensino, no Brasil, dentro dos moldes da Universidade de Harvard aconteceu na década de 70, e eram catalogados e distribuídos pela Central Brasileira de Casos. Esse sistema funcionou até a década de 80, mas depois foi desativado. A estratégia ressurgiu na última década (2000-2010), e aparece nos grandes eventos da área da administração como: o Encontro Anual da Associação de Pós-graduação e Pesquisa em Administração (ENANPAD) e o Encontro de Ensino e Pesquisa em Administração e Contabilidade (EnEPQ) aceitam a submissão de casos para ensino. Ademais, a Revista de Administração Contemporânea 
(RAC) da Associação Nacional de Pós-Graduação e Pesquisa em Administração (ANPAD) trabalha com uma seção dedicada a esses.

Além das ações especificadas anteriormente, existe uma revista que trabalha de forma exclusiva a metodologia do caso para ensino. A GV Casos - Revista Brasileira de Casos de Ensino em Administração, da Fundação Getúlio Vargas (FGV), que em 2015 atingiu seu $5^{\circ}$ volume e trouxe dois números por ano. De acordo com Diniz (2010), a revista busca alinhar as temáticas que possam conduzir a uma melhor forma de aprendizado em administração. O número de publicações da revista está demonstrado na Tabela 1.

Tabela 1. Distribuição das publicações dos casos para ensino em administração da revista GV Casos

\begin{tabular}{|c|c|c|c|c|}
\hline Ano & Volume & Número & Período & $\begin{array}{l}\text { Número de } \\
\text { Publicações }\end{array}$ \\
\hline 2015 & 05 & 02 & $\begin{array}{c}\text { Julho a } \\
\text { Dezembro }\end{array}$ & 09 casos \\
\hline 2015 & 05 & 01 & $\begin{array}{l}\text { Janeiro a } \\
\text { Junho }\end{array}$ & 07 casos \\
\hline 2014 & 04 & 02 & $\begin{array}{c}\text { Julho a } \\
\text { Dezembro }\end{array}$ & 08 casos \\
\hline 2014 & 04 & 01 & $\begin{array}{l}\text { Janeiro a } \\
\text { Junho }\end{array}$ & 08 casos \\
\hline 2013 & 03 & 02 & $\begin{array}{c}\text { Julho a } \\
\text { Dezembro }\end{array}$ & 08 casos \\
\hline 2013 & 03 & 01 & $\begin{array}{l}\text { Janeiro a } \\
\text { Junho }\end{array}$ & 05 casos \\
\hline 2012 & 02 & 02 & $\begin{array}{c}\text { Julho a } \\
\text { Dezembro }\end{array}$ & 06 casos \\
\hline 2012 & 02 & 01 & $\begin{array}{l}\text { Janeiro a } \\
\text { Junho }\end{array}$ & 06 casos \\
\hline 2011 & 01 & 02 & $\begin{array}{c}\text { Julho a } \\
\text { Dezembro }\end{array}$ & 06 casos \\
\hline 2011 & 01 & 01 & $\begin{array}{c}\text { Janeiro a } \\
\text { Junho }\end{array}$ & 08 casos \\
\hline
\end{tabular}

Fonte: Elaborado pelos autores (2016).

Com o passar dos anos o número de publicações de casos para ensino vem aumentando. Para constatar isso, pode-se observar os dados das publicações da GV Casos. Em 2015 a revista já havia publicado, nos 05 volumes, 71 casos para ensino, a maioria abordando temas ligados diretamente ao marketing e à estratégia, e recentemente apareceram casos ligados à gestão pública e social.

Embora tenha 71 publicações no ano, o número de submissões foi superior a esse dado. Em 2012 houve 37 pedidos, dos quais 12 foram aceitos, 16 rejeitados e 11 permaneciam em fase de análise. A taxa de rejeição ainda é alta, segundo a revista, de $42,9 \%$ e os descartes em sua maioria são por falta de adequação às diretrizes editoriais, como envio do caso em moldes de artigo acadêmico tradicional, uma descrição de um estudo de caso, como forma de método de pesquisa e não como ferramenta pedagógica, ou uma submissão incompleta, faltando as notas de ensino, por exemplo. A revista conta com 245 assinantes, dos quais 67 são do ano 2014. Esse número mostra o avanço que essa ferramenta acadêmica está trazendo, bem como a sua aceitação (DINIZ, 2010).

\section{Procedimentos metodológicos}

Nesta seção são apresentadas as principais decisões em relação ao processo de coleta, organização dos dados e procedimentos de análise. Para realização da análise da aplicação da estratégia do caso para ensino, escolheu-se o uso dessa ferramenta em três disciplinas de Marketing, sendo elas Administração Mercadológica I e II e Gestão de Serviços. A escolha das disciplinas se deu porque elas foram as únicas com as quais os alunos tiveram contato a estratégia do caso para ensino. Os respondentes da pesquisa foram os alunos matriculados nessas disciplinas, caracterizando uma amostra composta por 80 estudantes.

A escala utilizada foi derivada dos trabalhos de Ikeda, Veludo-de-Oliveira e Campomar (2007). A métrica desenvolvida pelos autores é formada por 23 itens divididos em sete fatores e com itens específicos para uso em cursos de marketing. As devidas adaptações foram realizadas, no intuito de que o questionário final se enquadrasse na realidade dos alunos participantes da pesquisa, ao tempo em que refletisse a capacidade de mensurar a percepção do uso da ferramenta pedagógica do caso para ensino. Foram excluídos 11 itens do questionário original, constituindo o instrumento de coleta de dados a partir de 12 afirmativas do tipo Likert, com variação de 1 (discordo totalmente) a 10 (concordo totalmente), agregados em quatro variáveis. Os itens e variáveis as quais se referem, são apresentados no Quadro 1. 
Quadro 1. Variáveis e os respectivos itens utilizados nesta pesquisa

\begin{tabular}{|c|c|}
\hline VARIÁVEIS & ITENS \\
\hline \multirow{3}{*}{ Uso do caso } & $\begin{array}{l}\text { Gostei da aplicação do caso em sala de } \\
\text { aula }\end{array}$ \\
\hline & $\begin{array}{l}\text { Uma aula com discussão de casos é } \\
\text { mais dinâmica }\end{array}$ \\
\hline & $\begin{array}{l}\text { Gosto quando aparecem diálogos no } \\
\text { texto do caso } \\
\text { Gostaria que os casos fossem usados } \\
\text { em outras disciplinas }\end{array}$ \\
\hline \multirow{3}{*}{$\begin{array}{c}\text { Desenvolvimento } \\
\text { de habilidades nos } \\
\text { estudantes }\end{array}$} & $\begin{array}{l}\text { Com a discussão de casos melhoro } \\
\text { minha argumentação }\end{array}$ \\
\hline & $\begin{array}{l}\text { O caso ajuda a melhorar minha } \\
\text { capacidade de comunicação }\end{array}$ \\
\hline & $\begin{array}{l}\text { Estudando com o método do caso } \\
\text { melhoro minha capacidade gerencial }\end{array}$ \\
\hline \multirow{3}{*}{$\begin{array}{c}\text { Preparação para o } \\
\text { uso do método } \\
\text { na sala de aula }\end{array}$} & $\begin{array}{l}\text { Li com bastante atenção o caso antes de } \\
\text { ir para a aula }\end{array}$ \\
\hline & É preciso preparo do aluno \\
\hline & $\begin{array}{l}\text { Teria grande motivação de vir preparado } \\
\text { para discutir casos em sala de aula }\end{array}$ \\
\hline \multirow{2}{*}{$\begin{array}{c}\text { Formato de } \\
\text { apresentação do } \\
\text { caso }\end{array}$} & $\begin{array}{l}\text { Gosto da maneira de como o caso é } \\
\text { escrito }\end{array}$ \\
\hline & $\begin{array}{l}\text { É fácil fazer a ligação do caso com as } \\
\text { teorias e conceitos da disciplina }\end{array}$ \\
\hline
\end{tabular}

Fonte: Adaptado de Ikeda, Veludo-de-Oliveira e Campomar (2007).

O próximo passo da pesquisa consistiu na aplicação da metodologia do caso para ensino em sala de aula. Foram aplicados os seguintes casos, escolhidos conforme o conteúdo relacionado às disciplinas ofertadas: "Caso para Ensino - Granado" (SASTRE, IKEDA, TOLEDO, 2012) para a disciplina de Administração Mercadológica I, "A gestão do marketing mix: como mexer no time que está ganhando?" (COSTA FILHO, et al., 2014) para a disciplina de Administração Mercadológica II e "Som Livre: mudar ou morrer?" (TRINTA, et al., 2011) para a disciplina de Gestão de Serviços. Os casos foram escolhidos considerando os objetivos e a ementa de cada disciplina.

A aplicação foi dividida em quatro etapas: na primeira ocorreu a disponibilização do caso para ensino em meio virtual para leitura prévia dos alunos; uma semana após a primeira etapa, ocorreu a apresentação e contextualização do caso em sala de aula, momento no qual também foram disponibilizadas as questões para discussões no próximo encontro; na terceira etapa, na semana subsequente, houve o debate do caso para ensino em sala de aula usando as respostas das questões da etapa anterior. A última etapa consistiu na aplicação do questionário com os 80 alunos da disciplina da graduação para avaliar a metodologia utilizada.

Após as etapas descritas anteriormente, os 80 questionários foram tabulados e analisados com uso do software R, como forma de facilitar a operacionalização estatística da pesquisa. Como a amostra é de pequena proporção, houve o cuidado para que os questionários fossem completamente respondidos, não apresentando na tabulação a existência de missing values e outliers.

Em seguida, procedeu-se a análise da adequação dos construtos. Primeiramente verificou-se a consistência psicométrica das escalas por meio da análise fatorial e análise de confiabilidade a partir do coeficiente Alpha de Cronbach. Foi excluído o item 'Gosto quando aparecem diálogos no texto do caso', por apresentar escore fatorial abaixo de 0,5 . Os demais itens foram mantidos, por apresentarem valores de Alpha e fatoriais aceitáveis. A confiabilidade dos itens, a variância extraída e escore fatorial mínimo dessas variáveis são expostas na Tabela 1.

Tabela 1: Resultados das Medidas de Consistência Psicométrica

\begin{tabular}{|l|c|c|c|}
\hline \multicolumn{1}{|c|}{ Variáveis } & Alpha & $\begin{array}{c}\text { Escore } \\
\text { Mínimo }\end{array}$ & $\begin{array}{c}\text { Variância } \\
\text { Extraída }\end{array}$ \\
\hline $\begin{array}{l}\text { Uso do caso para } \\
\text { ensino }\end{array}$ & 0,722 & 0,818 & $71,15 \%$ \\
\hline $\begin{array}{l}\text { Desenvolvimento } \\
\text { de habilidades } \\
\text { nos estudantes }\end{array}$ & 0,761 & 0,738 & $67,85 \%$ \\
\hline $\begin{array}{l}\text { Preparação para o } \\
\text { uso da estratégia } \\
\text { em sala de aula }\end{array}$ & 0,681 & 0,699 & $61,48 \%$ \\
\hline $\begin{array}{l}\text { Formato de } \\
\text { apresentação do } \\
\text { caso para ensino }\end{array}$ & 0,470 & 0,811 & $65,71 \%$ \\
\hline
\end{tabular}

Fonte: Dados da pesquisa (2016).

Ainda sobre tais variáveis, foi extraída a média de cada respondente e essas foram ponderadas pelo seu 
respectivo escore fatorial, permitindo gerar, por fim, as variáveis agregadas: uso do caso, desenvolvimento de habilidades, preparação do aluno e formato de apresentação do caso. Após a adequação e tratamento inicial dos dados, estes estiveram prontos para posterior análise das medidas centrais e teste de hipóteses. A análise dos resultados desse estudo é apresentada na seção a seguir.

\section{Análise dos resultados}

\section{Análise descritiva da Amostra}

Os dados de caracterização da amostra da pesquisa mostram que a maioria dos estudantes tem o Ensino Superior Incompleto (90\%). Alunos do sexo masculino representam 61,3\% dos respondentes, enquanto 38,8\% são do sexo feminino. A maioria dos respondentes está na faixa de 21 a 25 anos (58,8\%), ficando os demais respondentes com idades distribuídas nas demais faixas de idade. Apesar da maioria estar em sua primeira graduação, percebe-se que a turma possui pessoas formadas ou com pós-graduação. Em relação ao período do curso, $5 \%$ afirmaram estar cursando o terceiro período, 3,8\% cursam o quinto período, $43,8 \%$ o sétimo período, $10 \%$ o nono período e $37,5 \%$ não quiseram afirmar ou não possuem um período regular. A caracterização da amostra reflete que os dados possuem uma heterogeneidade suficientemente apropriada para análise dos resultados das variáveis e das hipóteses do estudo. Esses resultados são demonstrados no tópico seguinte.

\section{Análise das Variáveis e ltens que compõem a pesquisa}

Realizada a análise da consistência psicométrica das escalas e ponderação das variáveis, foram extraídas as medidas de média, desvio padrão, assimetria e curtose utilizando as variáveis agregadas. A Tabela 2 mostra os resultados do cálculo dessas medidas.

Tabela 2. Medidas Descritivas

\begin{tabular}{|l|c|c|c|c|}
\hline \multicolumn{1}{|c|}{ Variáveis } & Média & Desvio Padrão & Assimetria & Curtose \\
\hline $\begin{array}{l}\text { Uso do caso para } \\
\text { ensino }\end{array}$ & 8,59 & 1,38020 & $-1,417$ & 1,761 \\
\hline $\begin{array}{l}\text { Desenvolvimento } \\
\text { de habilidades nos } \\
\text { estudantes }\end{array}$ & 8,35 & 1,34510 & $-1,275$ & 1,856 \\
\hline $\begin{array}{l}\text { Preparação para o uso } \\
\text { da estratégia em sala de } \\
\text { aula }\end{array}$ & 8,51 & 1,34862 & $-1,761$ & 3,895 \\
\hline $\begin{array}{l}\text { Formato de } \\
\text { apresentação do caso } \\
\text { para ensino }\end{array}$ & 8,30 & 1,29872 & $-1,285$ & 1,690 \\
\hline
\end{tabular}

Fonte: Dados da pesquisa (2016).

Os resultados da média indicam que todas as variáveis foram avaliadas positivamente pelos alunos, apresentando valores acima de 8 . A partir desses valores, é possível auferir que os alunos que responderam à pesquisa avaliam de forma positiva o uso do caso para ensino em sala de aula, reconhecem o desenvolvimento de habilidades através dessa metodologia, realizam a preparação anterior necessária para o uso da estratégia e julgam apropriado o formato de apresentação dela. Os valores de desvio padrão mostram que as variáveis mantiveram um padrão de respostas equivalentes e que se distanciam numa baixa intensidade em relação à média.

Em relação aos valores de formato, assimetria e curtose, nota-se que ambos os indicadores se distanciam 
consideravelmente do valor padrão (zero), o que pode indicar que os valores não possuem uma distribuição uniforme, logo, apresentam problemas na normalidade dos dados. Tal constatação evidencia que é preferível o uso de modelos que desconsiderem como pressuposto a normalidade dos dados para o teste de hipóteses. O próximo tópico explicitará o modelo utilizado e os resultados dos testes de hipótese.

\section{Teste de Hipóteses}

Os testes de hipótese indicam se as variáveis preditas (Uso do caso para ensino, Preparação para o uso da estratégia e Formato de apresentação do caso para ensino), influenciam no desenvolvimento de habilidades nos estudantes. Para realização dos testes, foi utilizada a modelagem Theil-Sen. A escolha dessa modelagem foi dada devido à análise de assimetria e curtose indicar que os dados da pesquisa não seguem uma distribuição normal. Tão logo, o Modelo de Regressão Theil-Sen é livre dos pressupostos de normalidade dos dados. O modelo de regressão Theil-Sem foi baseada em bootstrapping com 400 reamostragens para inferência dos parâmetros. Os testes foram realizados com auxílio do software R. Os resultados da regressão são apresentados na tabela 3.

Tabela 3. Resultado do modelo de regressão Theil-Sen

\begin{tabular}{|c|c|c|c|c|c|}
\hline \multirow{2}{*}{ Variável } & \multirow{2}{*}{ Beta } & \multirow{2}{*}{ E- Padrão } & \multirow{2}{*}{ P-valor } & \multicolumn{2}{|c|}{ Intervalo de confiança } \\
\hline & & & & $2,5 \%$ & $97,5 \%$ \\
\hline Intercepto & 1,85 & 0,717 & 0,20 & 0,285 & 3,271 \\
\hline $\begin{array}{c}\text { Uso do caso para } \\
\text { ensino }\end{array}$ & 0,640 & 0,141 & 0,000 & 0,380 & 0,920 \\
\hline $\begin{array}{l}\text { Preparação para o } \\
\text { uso da estratégia } \\
\text { em sala de aula }\end{array}$ & $-0,087$ & 0,141 & 0,455 & $-0,409$ & 0,162 \\
\hline $\begin{array}{l}\text { Formato de } \\
\text { apresentação do } \\
\text { caso para ensino }\end{array}$ & 0,218 & 0,162 & 0,140 & $-0,510$ & 0,565 \\
\hline $\begin{array}{l}\text { Pseudo R2 de } \\
\text { Wilcox }\end{array}$ & & & 0,402 & & \\
\hline
\end{tabular}

Fonte: Dados da pesquisa (2016).

Observados os resultados apresentados na tabela 3, é possível verificar que apenas a variável "Uso do caso ensino" influencia no desenvolvimento das habilidades dos estudantes, apresentando p-valor menor que 0,05. As variáveis "Preparação para o uso da estratégia em sala de aula" e "Formato de apresentação do caso para ensino", apresentaram respectivamente p-valores 0,455 e 0,140 , ou seja, a hipótese de que essas variáveis influenciam no desenvolvimento das habilidades dos estudantes não pode ser confirmada. Percebe-se que o modelo de regressão utilizado possui a capacidade de explicar 40,2\% da variação na variável desenvolvimento de habilidades dos estudantes, a partir do pseudo R2 robusto de Wilcox, sendo esse valor considerado relevante na apropriação do modelo.

Um resumo das hipóteses e dos resultados do teste é explicitado no quadro 2. No tópico seguinte serão realizadas as discussões com base nos resultados encontrados. 
Quadro2. Hipóteses da Pesquisa

\begin{tabular}{|c|l|c|}
\hline Hip. & \multicolumn{1}{|c|}{ Representação } & Conclusão \\
\hline H1 & $\begin{array}{l}\text { A predisposição para o uso do caso para ensino pelos alunos influencia } \\
\text { positivamente no desenvolvimento de habilidades dos mesmos. }\end{array}$ & Confirmada \\
\hline H2 & $\begin{array}{l}\text { A preparação dos alunos para o uso do caso para ensino na sala de aula influencia } \\
\text { positivamente no desenvolvimento de habilidades dos mesmos. }\end{array}$ & Rejeitada \\
\hline H3 & $\begin{array}{l}\text { A formatação do caso para ensino influencia positivamente no desenvolvimento } \\
\text { de habilidades nos estudantes. }\end{array}$ & Rejeitada \\
\hline
\end{tabular}

Fonte: Dados da pesquisa (2016).

\section{Discussão dos Resultados}

Como exposto no Quadro 2, vê-se que a hipótese 1, que avalia "a predisposição para uso do caso pelos alunos influencia positivamente no desenvolvimento de habilidades dos mesmos" foi confirmada, mostrando que, por meio da discussão de um caso é possível melhorar a argumentação dos alunos, e que o uso do caso é capaz de melhorar a capacidade de comunicação, bem como a capacidade gerencial destes.

Quanto às hipóteses 2 e 3, que tratam da preparação dos alunos (média 8,51) e da formatação do caso para ensino (média 8,30), estas foram rejeitadas neste estudo, levando-se em consideração o desenvolvimento de habilidades nos alunos. Entretanto, julgam-se as variáveis importantes para entendimento de alguns aspectos, como a percepção dos alunos acerca do uso do caso em sala, a forma como eles se prepararam para estudar usando o caso para ensino, bem como a maneira em que o caso estava apresentado. O estudo mostra que tais variáveis não se relacionam, ainda que possam vir a influenciar na aprendizagem. Pode-se dizer que tais variáveis sejam importantes no processo de cognição do uso do caso, influenciando na leitura, no relacionamento dos conhecimentos teóricos trazidos pelo caso, porém, neste estudo, elas não apresentaram relevância estatística para que habilidades sejam desenvolvidas nos alunos.

\section{Considerações finais}

Este trabalho buscou avaliar o uso da estratégia do caso para ensino como ferramenta pedagógica no curso de administração de uma Universidade Pública no estado do Ceará. Para tanto, os discentes de três disciplinas foram apresentados à metodologia que tem como propósito alocar o estudante como protagonista no processo de aprendizado dentro da sala aula, fazendo com que o mesmo vivencie situações reais que exijam uma tomada de decisão.

Estes resultados mostram que apesar da referida estratégia pôr o aluno como principal ator dentro do processo de ensino e aprendizagem, há algumas barreiras a enfrentar para a eficiência da metodologia, como a inexperiência dos alunos quanto ao caso para ensino, por exemplo. Entretanto, pode-se dizer que a aplicação no curso de Administração teve êxito, quanto ao escopo das disciplinas abordadas neste trabalho. No âmbito gerencial o desempenho satisfatório deste método é importante uma vez que desenvolve o senso crítico, a capacidade de visualizar outras análises perante a situação da organização, características estas necessárias diante da globalização e da concorrência entre as organizações.

Verificou-se, ainda, que os estudantes concordam que as aplicações de casos em sala tornam as aulas mais dinâmicas, bem como estão abertos para que a metodologia fosse aplicada em outras disciplinas. No entanto, apesar de concordarem que é necessário preparo do aluno e que no geral eles estão motivados para discussão do caso, percebeu-se que não houve uma leitura atenta do material. Outro ponto a ser citado de acordo com Faria e Figueiredo (2013) é a própria redação de casos brasileiros, a maior parte dos casos feitos no Brasil apresentam problemas nas notas de ensino, prejudicando assim a aplicação em sala de aula. 
A limitação deste trabalho está relacionada ao tamanho da amostra. Embora a pesquisa tenha sido realizada no período de um ano, a quantidade de alunos nas disciplinas era reduzida, fato que tornou a amostra pequena, sendo necessário o procedimento de bootstrapping para a realização do teste de hipóteses.

Sugerem-se como pesquisas futuras a avaliação dos professores quanto ao uso da ferramenta do caso para ensino, que podem ser feitas com docentes que ministram disciplinas que abordam as temáticas de marketing ou de disciplinas que enfatizem outras áreas, verificando o papel de professores e a aplicação do caso na visão deles. Ademais, recomenda-se pesquisas com abordagem qualitativa para analisar perspectivas diferenciadas daquelas analisadas em pesquisas quantitativas, caso deste estudo.

\section{Referências bibliográficas}

AMBROSINI, V.; BOWMAN, C.; COLLIER, $\mathrm{N}$. Using teaching case studies for management research. Strategic Organization, v. 8, n. 3, p. 206229, 2010. Disponível em: http://journals.sagepub. com/doi/pdf/10.1177/1476127010374254. Acesso em: 20 de fev. 2016.

CHANG, J. Strategic management: an evaluation of the use of three learning methods in Hong Kong. Developments in Business Simulation \& Experiential Learning, v. 30, p. 146-151, 2003. Disponível em: https://journals.tdl.org/absel/index. $\mathrm{php} / \mathrm{absel} / \mathrm{article} / \mathrm{view} / 713 / 682$. Acesso em: $22 \mathrm{de}$ mar 2016.

CHANG, J.; JENNINGS, D.; TO, C.; SUN, L. Strategic management: An evaluation of the use of three learning methods in China. Developments in Business Simulation \& Experiential Exercises, v. 32, p. 76-81, 2005. Disponível em: https:// journals.tdl.org/absel/index.php/absel/article/ view/559/528. Acesso em: 03 de mar 2016.

COSTA FILHO, C. G.; MESQUITA, J. M. C.; FERNANDES, R. B.; CAIXETA, R. P. CASTRO, C. C. A gestão do marketing mix: como mexer no time que está ganhando? GV Casos, v 4, n. 1, p. 1-9, 2014. Disponível em: http://bibliotecadigital.fgv.br/ ojs/index.php/gvcasos/article/view/9297/19835. Acesso em: 15 de mar 2016.
CURADO, I. B. O desenvolvimento dos saberes administrativos em São Paulo: uma análise histórica. 2001. 191 p. Tese (Tese de Doutorado) Fundação Getúlio Vargas - Escola de Administração de Empresas de São Paulo, São Paulo, 2001. Disponível em: http://bibliotecadigital.fgv.br/ dspace/bitstream/handle/10438/4507/1200101196. pdf? sequence $=1 \&$ is Allowed $=y$. Acesso em: 07 de mar 2016.

DINIZ, Eduardo. Todas as Edições. FGV, 2010. Disponível em: http://bibliotecadigital.fgv.br/ojs/ index.php/gvcasos/issue/archive. Acesso em: 22 de jan 2016.

FARIA, M.; FIGUEIREDO, K. F. Casos de ensino no Brasil: análise bibliométrica e orientações para autores. Revista de Administração

Contemporânea, v. 17, n. 2, p. 176-197, 2013.

Disponível em: http://www.scielo.br/pdf/rac/ v17n2/04.pdf. Acesso em: 30 de jan 2016.

GALLON, S.; RODRIGUES, C, M, C. Curso de Administração da Universidade Federal de Santa Maria/Ufsm: A percepção dos professores e alunos sobre o tema práticas pedagógicas. In: Seminários em Administração, 11., 2008, São Paulo. Anais... São Paulo: FEA-USP, 2008. Disponível em: http:// seer.uscs.edu.br/index.php/revista_gestao/article/ viewFile/93/56. Acesso em 13 de fev 2016.

GIL, A. C. Elaboração de casos para o ensino de administração. Revista Contemporânea de Economia e Gestão, v. 02, n. 02, p. 07-16, 2004. Disponível em: http://www.periodicos.ufc.br/index. $\mathrm{php} /$ contextus/article/viewFile/571/553. Acesso em: 03 de mar 2016.

GREENHALGH, A. Case method teaching as science and art: a metaphoric approach and curricular application. Journal of Management Education, v. 31, n. 2, p. 181-194, 2007.

HAWES, J. M. Teaching is not telling: the case method as a form of interactive learning. Journal for Advancement of Marketing Education, v. 5, p. 47-54, 2004. Disponível em: http://www.mmaglobal. org/publications/JAME/JAME-Issues/JAME-2004Vol05-Issue1/JAME-2004-Vol05-Issue1-Hawespp47-54.pdf. Acesso em: 06 de fev 2016.

HISTÓRIA da Administração. CFA, 2014. Disponível em: < http://www.cfa.org.br/ administracao/historia-da-profissao > Acesso em: 20 de jan 2016. 
IKEDA, A. A.; VELUDO-DE-OLIVEIRA, T. M.;

CAMPOMAR, M. C. A tipologia do método do caso em administração: usos e aplicações. Organizações e Sociedade, v. 34, n. 12, p. 141-159, 2005. Disponível em: http://www.scielo.br/pdf/osoc/ v12n34/a09v12n34.pdf. Acesso em: 22 de jan 2016.

IKEDA, A. A.; VELUDO-DE-OLIVEIRA, T. M.; CAMPOMAR, M. C. O método do caso no ensino de marketing. RAC Eletrônica, v. 1, no 3, p. 52-68, 2007. Disponível em: http://www.anpad.org.br/ periodicos/arq_pdf/a_664.pdf. Acesso em: 29 de jan de 2016.

KRUEL, A. J.; SANTOS, C. G. Estudo de caso ou caso para ensino: Uma análise de casos produzidos em um curso de especialização no sul do Brasil. In: ENCONTRO DA ASSOCIAÇÃO NACIONAL DE PÓS-GRADUAÇÃO E PESQUISA EM ADMINISTRAÇÃO. 32., 2008, Rio de Janeiro. Anais... Rio de Janeiro: ANPAD. Disponível em: https://www.researchgate.net/ publication/266385851_Estudo_de_Caso_ou_Caso_ para_Ensino_Uma_Analise_de_Casos_Produzidos_ em_um_Curso_de_Especializacao_no_Sul_do_ Brasil. Acesso em: 14 de jan 2016.

PLEBANI, S.; DOMINGUES, M. J. C. S. A utilização dos métodos de ensino e a formação de competências gerenciais: uma análise no curso de administração. In: ENCONTRO ANUAL DA ASSOCIAÇÃO NACIONAL DOS CURSOS DE GRADUAÇÃO EM ADMINISTRAÇÃO, 19., 2008, Curitiba. Anais... Curitiba: ANGRAD, 2008.

PPC - Plano Pedagógico do Curso. Universidade Federal do [x], 2006.

ROESCH, S. M. A; FERNANDES, F. Como

Escrever Casos para o Ensino de Administração.

São Paulo: Atlas, 2007.

SASTRE, P. T. N.; IKEDA, A. A.; TOLEDO,

G. L. Caso para ensino - Granado.In:

ENCONTRO DA ASSOCIAÇÃO NACIONAL DE PÓS-GRADUAÇÃO E PESQUISA EM ADMINISTRAÇÃO. 36., 2012, Rio de Janeiro. Anais... Rio de Janeiro: ANPAD. Disponível em: http:/ /www.anpad.org.br/admin/pdf/2012_ EPQ2680.pdf. Acesso em: 20 de jan 2016.

SILVA, L. C.; DOMINGUES, M. J. C. S. Métodos de ensino no curso de administração de empresas: aplicação e satisfação. In: ENCONTRO ANUAL
DA ASSOCIAÇÃO NACIONAL DOS CURSOS

DE GRADUAÇÃO EM ADMINISTRAÇÃO, 17. 2006, São Luís. Anais... São Luís: ANGRAD, 2006. Disponível em: http://sinop.unemat.br/site_antigo/ prof/foto_p_downloads/fot_11839metodos_de_ ensin_no_cubso_de_adm_pdf_Metodos_de_Ensin_ no_Curso_de_Adm.pdf. Acesso em: 03 de mar 2016.

TRINTA, J. L., ALTAF, J. G., ABDALLA, M. M., TROCCOLI, I. R. Som Livre: mudar ou morrer? Rev. Bras. de Casos de Ensino em Administração, v 1, n. 2, p. 1-11, 2011. Disponível em: http://bibliotecadigital.fgv.br/ojs/index.php/ gvcasos/article/view/3539/2314. Acesso em: 17 de fev 2016.

YIN, Robert K. Estudo de caso: planejamento e métodos. $3^{\text {a }}$ Ed. Porto Alegre: Brookman, 2005. 